\title{
The temperature profile of an apple supply chain: A case study of the Ceres district
}

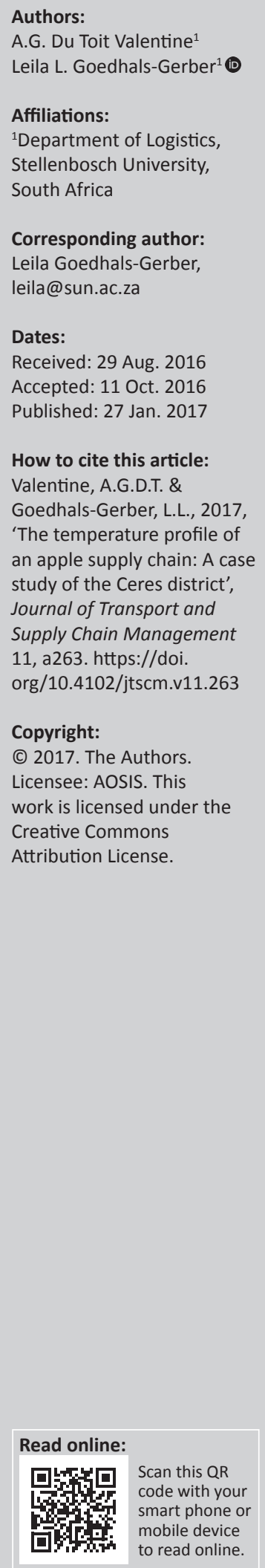

Background: There is a logistical gap in the first section of the apple supply chain that affects the temperature profiles of apples further downstream in the supply chain.

Objectives: This article's main objective is to confirm whether the logistics processes, in terms of the temperature profile of apples for the first 48 hours post-harvest, have an influence on the yield and/or quality of the fruit.

Method: Observations were made and informal interviews were conducted on three different farms to ascertain their perspective of the first section of the supply chain. Temperature trials were conducted to analyse the temperature profile of two apple varieties, namely Golden Delicious and Granny Smith on three different farms. These trials were conducted by placing an iButton ${ }^{\circledR}$ device on the inside and outside of an apple to measure the temperature readings every minute for the first 48 hours after picking.

Results: The research identified that it is not only at what time the apples are being harvested, but also at what time the apples are placed under cooling conditions to remove the field heat to obtain the recommended temperature profile within 48 hours. In addition, it was determined that effective and efficient picking at the right time (especially between 07:00 and 09:00) and the transportation of the apples directly, or as soon as possible after the apples came out of the orchard to the centralised cold storage facility, are key in ensuring the quality of the fruit and the temperature profile necessary for export.

Conclusion: This article identifies the need to improve operational procedures along the cold chain. From this research, it is clear that there are problem areas that affect the temperature profile of apples.

\section{Introduction}

According to J. Jordan (pers. comm., 26 February 2015), quality control manager at Goede Hoop Vrugte and previous inspection employee of the Perishable Products Export Control Board (PPECB), the temperature profile of apples is important for the grower to take note of, because it directly impacts the quantity and quality of fruit yield. Various factors play a role in affecting the temperature profile of apples. According to Thompson (2002), the most important factor to consider is temperature. Other factors include geographical location, loading and unloading practices, transportation methods and the time of day that the fruits are harvested (Food and Agriculture Organisation of the United Nations 2016; Jordan 2015; Siddiqui, Zavala \& Hwang 2016). In this study, the geographical locations of farms investigated are located in the Kouebokkeveld, Droëhoek and Ceres valleys. In addition, the different methods of loading, unloading and transportation on and from each of the three farms and the centralised cold storage facility used by all three farms are examined. The trade-off between the time of picking and fruit quality is also considered.

There is a logistical gap in the first section of the supply chain that influences the temperature profile of apples (Haasbroek 2013). Temperature variation comes in extreme forms in the Ceres district and directly influences the apples' maturity and temperature profile. Winter temperatures can plummet to below $5{ }^{\circ} \mathrm{C}$, whilst the temperature in summer can reach beyond $40^{\circ} \mathrm{C}$ (Ceres.org. za 2015). It is necessary to stay up-to-date and informed of the change in climate and processes that are followed on farms with respect to the temperature profile of apples. Different growers utilise diverse supply chains and each has their own unique way to perform optimally. This article focuses on the first section of the apple supply chain. There are very little recent academic research or journal articles on this topic because of its specific nature, and growers do not have the time during the harvest season to run tests on the temperature profile of apples (Jordan 2015). 
Best practices with regard to the temperature profile of apples from a logistical perspective are essential. This research was conducted in the Ceres district with specific focus on two apple varieties, namely Golden Delicious and Granny Smith, and on three different farms (referred to as Farm A, Farm B and Farm $C$ to protect the confidentiality of the farms). If the best practices are not in use on farms, or at the centralised cold storage facility, it may have a serious influence on the product outcome (J. Valentine, pers. comm., 24 February 2015).

The following section provides a literature review on the apple industry and the logistical challenges faced in terms of the temperature profile of apples (Golden Delicious and Granny Smith). It provides guidelines set out by the PPECB that are put in place to help ensure that the best practices are followed with regard to the temperature profile of apples. Temperature trials were conducted on each variety on the three different farms. Analysis of the data is provided and problems identified during the first 48 hours after harvest are discussed. This article concludes by highlighting the reasons why certain farms perform better.

\section{Literature review}

According to Jobling (2002), the most significant factor in post-harvest management is temperature management. Even small deviations from the required temperature can significantly impact the shelf life of fresh produce and its value (Intelliflex 2012). Therefore, any temperature break at any stage along the cold chain will result in a reduction in shelf life. The longer the cold chain is broken, the greater the impact will be on the shelf life of the fruit. In addition, frequent short breaks in the cold chain can be as damaging to the shelf life of the fruit as one long break (M. Dodd, pers. comm., 13 July 2015), and temperature breaks are additive (Goedhals-Gerber 2015).

According to Thompson et al. (2008), temperature has the greatest influence on apple's deterioration rates, potential market life and fruit quality (confirmed by the Department for Environment, Food and Rural Affairs, n.d.). All perishable products have a finite lifespan and their quality is constantly deteriorating from the moment of harvest. Fruit quality directly influences the price of the product, and any rise in the temperature of the product above the optimum pulp level will increase the deterioration rate, resulting in a reduction in fruit quality and price (Kansal 2014).

According to Arin and Akdemir (2004), in practice, cooling down fruit to its optimum pulp temperature is the most active method to slow down the ripening process of fruit and vegetables. However, it is important to note that the cold chain can only preserve and not improve the quality of perishable products after harvest (Freiboth et al. 2013).

Each farm has their own supply chain regarding apple handling, transport and storage. A generic apple supply chain from picking until 48 hours post-harvest is explained. Factors that can affect the temperature profile of apples must be considered, including the geographical location of farms, different methods of loading, unloading and transportation, and the trade-off between the time of harvesting and fruit quality.

\section{A generic apple supply chain}

Apples are picked in the early morning or during the day, depending on whether the apple must be picked urgently or not and whether the maturity and temperature are at the right level. The first section of the supply chain of apples begins at the farm where the apple is harvested into a picking bag (Haasbroek 2013). From here, the picker empties the picking bag filled with apples into a wooden bin lined with plastic to prevent bruising and rubbing and to keep the ambient temperature at a reasonably cold level (Birch 1993). These bins are typically placed on a tractor-trailer combination, usually five trailers with a bin on each trailer and positioned in or just outside the orchard.

After the five bins are filled, the tractor transports the apples to the area where the bins are loaded onto a truck, which transfers the apples to a temporary cold storage facility on the farm. This is usually a farm pack house, a loading bay next to the orchard or a general fruit storage facility where the apples are temporarily stored before they are transported to the centralised cold storage facility used by the farm (Birch 1993). The apple bins are transported within 24 hours and unloaded at the cold storage facility (Crouch 2003). The bins are put in either controlled air (CA) rooms for long-term storage or regulated air (RA) rooms for temporary storage (Bartsch \& Blanplied 1984).

Figure 1 illustrates a supply chain of an apple from harvest until 48 hours later, starting by picking the fruit and placing the iButton ${ }^{\circledR}$ device inside and outside of the apple and ending when the 48 hours after picking is completed. In between, there are a number of segments, including the staging of bins after the apples have been picked, the loading of bins on the farms, transporting to the centralised cold storage facility and unloading the bins into cold storage for the remainder of the 48 hours.

\section{Geographical location of the fruit farms under investigation}

Research conducted on Kiwi fruit by Mowat and Kay (2007) showed that variations in fruit quality occur between orchards and growing regions. Shahidi et al. (2004) identified that the geographical location of the fruit farms has an impact on the quality of citrus fruit, whilst Siddiqui et al. (2016) agreed that the geographical location of the farm where the fruit is grown impacts the quality of the fruit.

The geographical location of the three farms used in this research is spread out over the Ceres district. These farms were chosen to compare different areas within the district with one another. Different areas have different climates (P. De Vries, pers. comm, 03 March 2015). Farm C, 52 km 


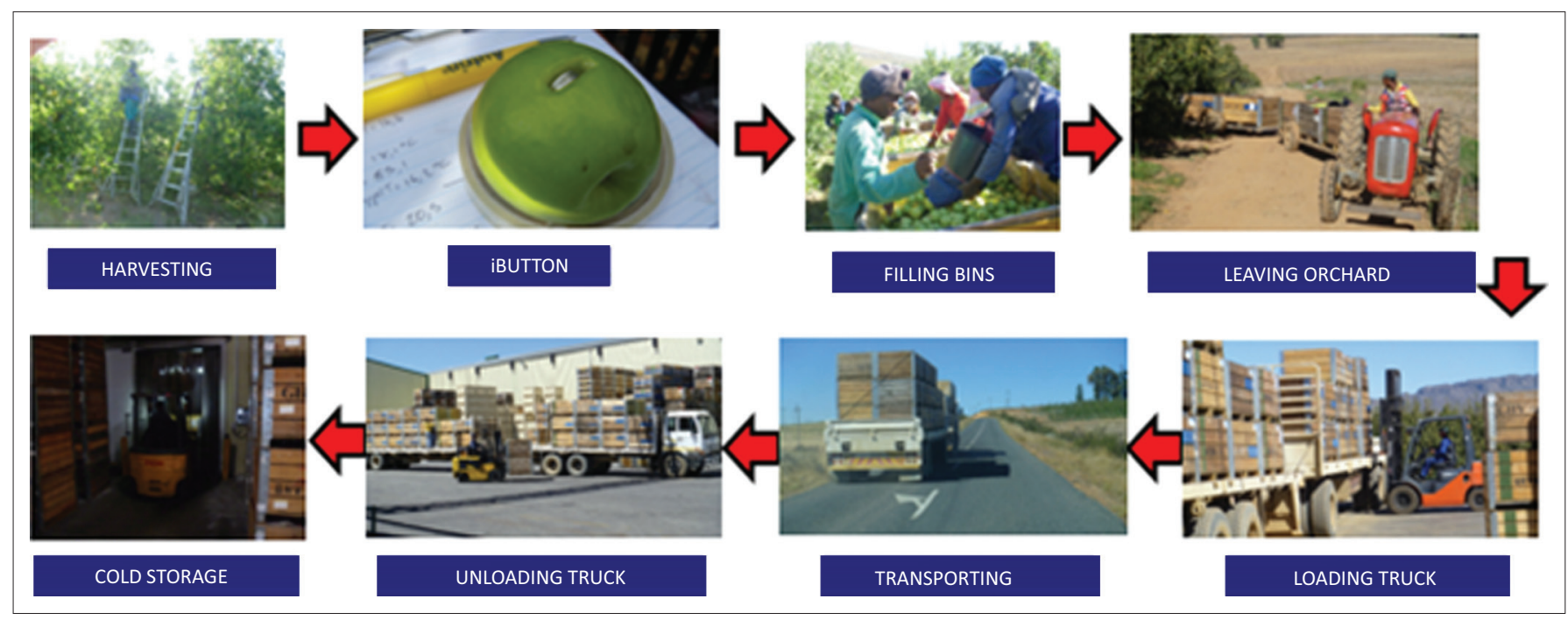

Source: Valentine, A.G.D., 2015. The temperature profile of an apple supply chain, from the picking process until 48 hours after picking: A case study of the Ceres district, Unpublished Honours Assignment. Stellenbosch: Stellenbosch University

FIGURE 1: A flow diagram of the supply chain of an apple until 48 hours post-harvest.

away from the centralised cold storage facility, is situated in the Kouebokkeveld area where it is usually colder than any other area in the district. Farm A, $34 \mathrm{~km}$ away from the centralised cold storage facility, is situated in the Droëhoek area, and Farm B, $9 \mathrm{~km}$ away from the centralised cold storage facility, is situated in the Ceres valley.

\section{Transportation systems and handling methods}

The globalisation of the trade of perishable products is creating a need for better transportation systems and handling methods to preserve produce quality (Vigneault et al. 2009). Loading, unloading and transportation jolts cause bruising. Therefore, it is recommended to use cushioning material to preserve the post-harvest quality of fresh produce (Ahmad \& Siddiqui 2016). According to the Food and Agriculture Organisation of the United Nations (2016), the method of transportation of fruit from the farm to the pack house influences the quality of the product at the final destination.

All three farms use different handling techniques for loading, unloading and transporting apples from the farm to the centralised cold storage facility. Some of the farms make use of a pack house to temporarily store their fruit; whilst others use a loading bay close to the orchard to load (usually between 18 and 68 bins) and transport the apples to the centralised cold storage facility.

\section{Time of harvest}

Harvesting apples at just the right time is essential, not only to obtaining the highest quality fruit but also to maximise the storage life. Each apple variety has its own maturation time and can be influenced by weather conditions during the growing season (Grant 2016). The trade-off between the time of harvesting and fruit quality must be made. According to Crouch (2003), Golden Delicious apples are picked later in the morning once the dew has evaporated from the fruit to improve the fruit quality (confirmed by Jordan 2015). This has a major impact on the temperature profile of apples. Time of harvesting apples is crucial and one must choose between maintaining a low temperature by harvesting in the early morning or ensuring there are fewer bruises and a better quality fruit by waiting for the dew to dry out (Crouch 2003). Keeping the apples at a standard cooling temperature also slows down decay by reducing the rate of perspiration and minimising water loss (Ngcobo 2010).

\section{Problem investigation and research objectives}

The temperature profile of apples is vital to growers, because it directly impacts either the quality or quantity of harvest (Jordan 2015). Three farms in the Ceres district were investigated along with two different varieties of apples. As mentioned in the introduction section, the geographical location of farms, different methods of loading, unloading and transportation on and from farms to the centralised cold storage facility, and the trade-off between the time of picking and fruit quality could have an impact on the temperature profile of apples. When these methods are compared with best practices, PPECB protocols and Hortgro standards, possible gaps can be seen (Hortgro 2015). Hortgro set standards on how to effectively optimise the apple supply chain according to certain temperature levels. This article focuses on the first section of the apple supply chain. The literature review shows that there are different supply chains for each grower and each has their own unique way to perform optimally.

This article's main objective is to confirm whether the logistics processes, in terms of the temperature profile of apples from the picking process until 48 hours post-harvest, have an influence on the yield and/or quality of the fruit. There are three subobjectives. Firstly, to determine whether the different handling techniques for loading, unloading and transportation on and from farms to the centralised cold storage facility impact on the temperature profile of apples. 
Secondly, to establish whether the geographical location of farms in the Ceres district has an impact on the temperature profile of apples and, lastly, to identify the optimal trade-off between the time of harvesting and fruit quality, specifically for the Golden Delicious apple variety.

\section{Research method}

This article is approached as a case study. An empirical methodology was followed to conduct the research.

Primary and secondary data were used in this study. A literature review was performed to obtain a better understanding of existing research (secondary data) in the field of the temperature profiles of apples. Secondary data were collected and analysed from a variety of sources, including journal articles and research reports, Hortgro, Experico, theses and farms in the Ceres district. In addition, the PPECB protocols and Hortgro standards were used to compare the supply chains of each farm to identify whether the farms operate according to the generic standard. In these protocols and standards documents, there are temperature metrics that were used to compare the farms accordingly.

Primary data were collected through observations, surveys, interviews and temperature trials. Temperature trials were conducted to determine whether the temperature profiles differ from the three farms in the Ceres district. Temperature recording devices (Maxim's iButton ${ }^{\circledR}$ ) were used to determine the temperature profile throughout the first section of the supply chain. These devices were placed both on the inside and on the outside of the apples to monitor and record the temperature reading every minute. The picking of apples took place between 08:00 and 09:00. Observations were made and informal interviews were conducted to obtain the perspective of people in the industry regarding the temperature profile of apples. After the temperature trials, the data were converted from the iButton ${ }^{\circledR}$ software into an MS Excel format, analysed and presented in a format that answers the research objectives.

\section{Research design}

The temperature trials were essential for this case study and indicated the temperature profiles of the different varieties of apples from the three different farms. To compare and analyse the results, the trials had to be conducted in exactly the same format. One trial was set up for each apple variety and repeated for each of the three different farms. Because of the short timeframe available, only one temperature trial for each apple variety was conducted at the three farms.

In every trial, 10 apples were picked from a certain orchard block to use in the trials. The iButton ${ }^{\circledR}$ device was placed on the inside and the outside of the apples between 08:00 and 09:00 on the morning of the specific trial day. Masking tape was used to tape the iButton ${ }^{\circledast}$ onto the outside of the apple. The masking tape was very thin to minimise the insulating effect it would have on the apple. The differences in temperature between the inside and outside of the apple (refer to Figure 2) indicate that the iButton ${ }^{\circledR}$ device is a very sensitive temperature-measuring device. After the iButton ${ }^{\circledR}$ device was inserted, the process was followed until the

\begin{tabular}{|c|c|c|c|c|c|c|c|c|c|c|c|c|}
\hline \multirow[b]{2}{*}{ Day conditions of trial } & \multicolumn{4}{|c|}{ Farm A } & \multicolumn{4}{|c|}{ Farm B } & \multicolumn{4}{|c|}{ Farm C } \\
\hline & \multirow{2}{*}{\multicolumn{2}{|c|}{ Goldens }} & \multicolumn{2}{|c|}{$\Delta=$} & \multicolumn{4}{|c|}{ 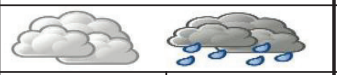 } & \multirow{2}{*}{\multicolumn{2}{|c|}{ 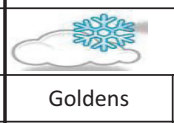 }} & \multicolumn{2}{|c|}{$\underset{\nabla}{\Delta}=$} \\
\hline Variety & & & Grar & nnys & Gold & dens & Grar & nnys & & & Gran & nnys \\
\hline Date & & \multicolumn{2}{|c|}{ 30-Mar } & \multicolumn{2}{|c|}{ 06-Mar } & \multicolumn{2}{|c|}{ 23-Mar } & \multicolumn{2}{|c|}{ 07-Mar } & \multicolumn{2}{|c|}{ 31-Mar } \\
\hline Day's forecasted average temperature on farm when picked & \multicolumn{2}{|c|}{$19.602^{\circ} \mathrm{C}$} & \multicolumn{2}{|c|}{$20.308^{\circ} \mathrm{C}$} & \multicolumn{2}{|c|}{$20.329^{\circ} \mathrm{C}$} & \multicolumn{2}{|c|}{$19.758^{\circ} \mathrm{C}$} & \multicolumn{2}{|c|}{$17.108^{\circ} \mathrm{C}$} & \multicolumn{2}{|c|}{$20.512^{\circ} \mathrm{C}$} \\
\hline Average temperature in orchard when picked 08:00 - 09:00 & \multicolumn{2}{|c|}{$15.4^{\circ} \mathrm{C}$} & \multicolumn{2}{|c|}{$19.602^{\circ} \mathrm{C}$} & \multicolumn{2}{|c|}{$14.61^{\circ} \mathrm{C}$} & \multicolumn{2}{|c|}{$16.07^{\circ} \mathrm{C}$} & \multicolumn{2}{|c|}{$14.56^{\circ} \mathrm{C}$} & \multicolumn{2}{|c|}{$14.22^{\circ} \mathrm{C}$} \\
\hline ¡Button device placed & In & Out & In & Out & In & Out & In & Out & In & Out & In & Out \\
\hline${ }^{\circ} \mathrm{C} 0$ hours after picked $-08: 00$ & 21.16 & 21.296 & 21.951 & 22.09 & 19.813 & 20.57 & 22.699 & 22.734 & 19.509 & 19.617 & 19.379 & 19.317 \\
\hline${ }^{\circ} \mathrm{C} 6$ hours after picked $-14: 00$ & 16.654 & 16.72 & 16.81 & 16.84 & 12.971 & 12.405 & 14.883 & 14.133 & 15.863 & 15.11 & 19.387 & 17.572 \\
\hline${ }^{\circ} \mathrm{C} 12$ hours after picked - 20:00 & 15.738 & 15.656 & 15.81 & 15.75 & 7.6178 & 7.2863 & 7.9005 & 7.4228 & 8.4411 & 8.1596 & 13.626 & 12.63 \\
\hline${ }^{\circ} \mathrm{C} 18$ hours after picked - 02:00 & 12.872 & 12.719 & 12.88 & 12.81 & 4.558 & 4.4219 & 3.9149 & 3.6709 & 5.3221 & 5.1401 & 9.7415 & 8.9865 \\
\hline${ }^{\circ} \mathrm{C} 24$ hours after picked - 08:00 & 9.8388 & 9.7025 & 9.8388 & 9.7025 & 3.184 & 3.1416 & 2.1413 & 2.0216 & 4.0683 & 3.9319 & 7.1628 & 6.6345 \\
\hline${ }^{\circ} \mathrm{C} 30$ hours after picked - 14:00 & 7.4243 & 7.2803 & 7.789 & 7.69 & 2.7598 & 2.7724 & 1.3876 & 1.3616 & 3.5506 & 3.4764 & 5.501 & 5.1525 \\
\hline${ }^{\circ} \mathrm{C} 36$ hours after picked - 20:00 & 5.6755 & 5.5466 & 5.6755 & 5.611 & 2.3903 & 2.3953 & 1.2308 & 1.228 & 3.621 & 3.5943 & 4.5443 & 4.2899 \\
\hline${ }^{\circ} \mathrm{C} 42$ hours after picked - 02:00 & 4.4203 & 4.2991 & 4.601 & 4.54 & 2.1704 & 2.2066 & 1.1835 & 1.1886 & 2.853 & 2.7151 & 3.8775 & 3.6546 \\
\hline${ }^{\circ} \mathrm{C} 48$ hours after picked - 08:00 & 3.6988 & 3.522 & 3.81 & 3.7 & 2.1625 & 2.191 & 1.2229 & 1.204 & 2.2491 & 2.1496 & 3.3439 & 3.1681 \\
\hline${ }^{\circ} \mathrm{C}$ as apples leave orchard on tractor & \multicolumn{2}{|c|}{$08: 57-15.19^{\circ} \mathrm{C}$} & \multicolumn{2}{|c|}{$09: 03-15.66^{\circ} \mathrm{C}$} & \multicolumn{2}{|c|}{$09: 19-15.75^{\circ} \mathrm{C}$} & \multicolumn{2}{|c|}{$08: 57-17.61^{\circ} \mathrm{C}$} & \multicolumn{2}{|c|}{$09: 00-14.48^{\circ} \mathrm{C}$} & $08: 55-1$ & $16.75^{\circ} \mathrm{C}$ \\
\hline${ }^{\circ} \mathrm{C}$ when apples are loaded onto truck & $11: 15-$ & $16.20^{\circ} \mathrm{C}$ & $11: 46-$ & $16.51^{\circ} \mathrm{C}$ & 10:55 - & $15.99^{\circ} \mathrm{C}$ & 10:41 - & $18.01^{\circ} \mathrm{C}$ & $09: 40-1$ & $14.65^{\circ} \mathrm{C}$ & $09: 45-1$ & $16.65^{\circ} \mathrm{C}$ \\
\hline${ }^{\circ} \mathrm{C}$ when unloaded at the centralised cold storage facility & $12: 40-$ & $16.95^{\circ} \mathrm{C}$ & 13:08- & $17.11^{\circ} \mathrm{C}$ & $11: 25-$ & $16.95^{\circ} \mathrm{C}$ & $11: 22-$ & $18.28^{\circ} \mathrm{C}$ & 11:58 - 1 & $18.13^{\circ} \mathrm{C}$ & 12:01 - 1 & $19.74^{\circ} \mathrm{C}$ \\
\hline Minimum ${ }^{\circ} \mathrm{C}$ & 3.699 & 3.521 & 3.81 & 3.7 & 2.155 & 2.117 & 1.184 & 1.189 & 2.249 & 2.144 & 3.234 & 3.167 \\
\hline Maximum ${ }^{\circ} \mathrm{C}$ & 21.29 & 21.32 & 21.951 & 22.09 & 19.97 & 20.88 & 22.7 & 22.73 & 19.591 & 19.62 & 19.388 & 19.35 \\
\hline Hottest & & & & & & & & & & & & \\
\hline
\end{tabular}

Source: Hortec, 2015, Designed and managed martin-endemann.com. 'Hortec/Weather Service', Hortec.co.za, viewed 29 March 2015, from http://www.hortec.co.za/weatherservices.html FIGURE 2: Weather information for Farm A, Farm B and Farm C on picking day. 
TABLE 1: Perishable products export control board ideal and minimum cold storage conditions for Golden Delicious and Granny Smith.

\begin{tabular}{|c|c|c|c|c|}
\hline \multirow[t]{2}{*}{ Criteria } & \multicolumn{2}{|c|}{ Ideal cold storage conditions } & \multicolumn{2}{|c|}{ Minimum cold storage conditions } \\
\hline & Golden Delicious & Granny Smith & Golden Delicious & Granny Smith \\
\hline Temperature & $\begin{array}{l}\text { Cooled to a core temperature of }-0.5^{\circ} \mathrm{C} \\
\text { within } 48 \text { hours }\end{array}$ & $\begin{array}{l}\text { Cooled to } 3^{\circ} \mathrm{C} \text { (or colder) within } 48 \text { hours after } \\
\text { harvest and maintain this for } 10 \text { days. Then } \\
\text { cool to }-0.5^{\circ} \mathrm{C} \text { as quickly as possible }\end{array}$ & $\begin{array}{l}4 \text { days to cool to } 2{ }^{\circ} \mathrm{C} \text { (or colder) } \\
+3 \text { days to } 0.5^{\circ} \mathrm{C} \text { (total of } 7 \text { days) }\end{array}$ & $\begin{array}{l}4 \text { days to } 3^{\circ} \mathrm{C} \text { (or colder) }+10 \text { days } \\
\text { to }-0.5^{\circ} \mathrm{C} \text { or } 0.5^{\circ} \mathrm{C} \text { (minimum } \\
\text { temperature: }-0.5^{\circ} \mathrm{C} \text {, total } 14 \text { days) }\end{array}$ \\
\hline
\end{tabular}

Source: Perishable Products Export Control Board (PPECB), 2015, PPECB, p. 9, viewed 13 July 2015, from http://www.ppecb.com

apples eventually reached the central cold storage facility. Once the data from the trial were analysed and sorted, clear information regarding the temperature profile of apples from different farms was identified. Although all three farms have a somewhat similar way of harvesting the two varieties of apples, there were vast differences in the results observed.

\section{Results \\ Impact on the apple temperature profile for the different handling techniques}

As mentioned previously, different ways of loading, unloading and transporting apples were observed at the three farms. These handling techniques and the way the apples were treated influence the temperature profile of apples. To check whether these farms perform well and that the necessary steps are taken with regard to the temperature profiles of the apples, every trial is compared to the best practice and PPECB protocol standards of cooling down apples for export. In Table 1, the PPECB export-qualifying specifications regarding ideal and minimum cold storage conditions for Golden Delicious and Granny Smith apples are tabulated.

The typical starting times for picking on the three different farms differ from one another. Farm A and Farm C usually start at 07:00 and Farm B only starts at 08:00 (A. Myburgh, pers. comm., 03 March 2015). In order to compare the temperature trials, the similar picking time had to be chosen.

Figures 2 and 3 indicate the average temperature inside and outside of the 10 different apples per trial per variety recorded by the iButton ${ }^{\circledR}$ device every minute. According to Table 1, the average temperature of the apples at 08:00 is higher than the average temperature in the orchard. This difference was caused by the researcher's body heat whilst placing the iButton ${ }^{\circledR}$ on the inside and outside of the apple. Although the Granny Smith average inside and outside temperatures are above the average of Golden Delicious, as can be seen in Figure 3, the Granny Smith apples cooled down much faster over the period of 48 hours. This is because Granny Smith apples are more sensitive to any fluctuations in temperature, whilst Golden Delicious apples maintain a consistent temperature for much longer (Crouch 2003). With reference to Figure 2, the weather and temperatures at Farm B allowed the Golden Delicious and Granny Smith apples to cool down the fastest within the 48 hours. This is mainly because both varieties were offloaded at the cold store earlier in the day than the other two farms. This is most likely because Farm B is the closest to the

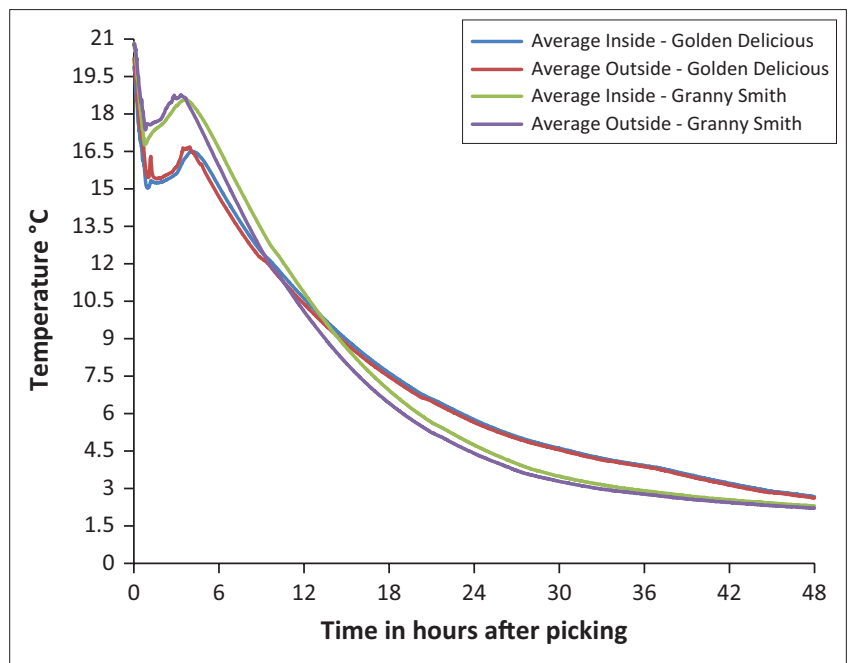

Source: Valentine, A.G.D., 2015. The temperature profile of an apple supply chain, from the picking process until 48 hours after picking: A case study of the Ceres district, Unpublished Honours Assignment. Stellenbosch: Stellenbosch University

FIGURE 3: Average inside and outside temperature readings.

centralised cold storage facility $(9 \mathrm{~km})$. Farm A's fruit cools down the slowest, because the fruit is only brought in during the middle of the day, when the hottest temperature of the day occurs. Despite Farm $C$ being the furthest away from the centralised cold storage facility, it manages to deliver the fruit to the centralised cold storage facility just before the hottest time of the day.

According to Figure 2, Farm B managed to reach the prescribed protocol within the ideal cold storage conditions for Granny Smith apples and the minimum cold storage conditions for Golden Delicious apples, as shown in Table 1. Farm C managed to reach the minimum cold storage conditions for both varieties, but only the Granny Smith apples from Farm A achieved the minimum cold storage conditions. Other possible reasons for the temperature fluctuations within the 48 hours after picking are: the physical orchard, size of picking teams, efficiency of pickers, storage of fruit until it is loaded for transportation to the centralised cold storage facility, number of forklifts, truck availability and size, loading efficiency and general transport (Jordan 2015).

In addition, Farm $\mathrm{C}$ is not as dense as Farm $\mathrm{A}$ and Farm B under the fruit trees and it is easier to access the trees to pick faster and more effectively. Farm $\mathrm{C}$ has four picking teams of 10 people per team in one orchard for either Golden Delicious or Granny Smith, whilst Farm A and Farm B have two picking teams of 10 people per team in one orchard. Whilst tractors transport the apples out of the orchard, only Farm C places a woven mat over bins to keep the temperature more consistent and the apples out of the direct sunlight. Pickers at Farm A and Farm $C$ are paid an amount per picking bag and therefore 
work more efficiently than at Farm B, where according to the black economic empowerment policy, the workers at the latter receive a fixed salary. With a fixed salary, there is less incentive to work efficiently. However, there are a minimum number of bags that the workers are required to pick to qualify for their full salary. Farm C makes use of a loading bay, where the Granny Smith apples are left in the sun before being transported to the centralised cold storage facility, whilst the Golden Delicious apples are temporarily stored in a large storage facility on the farm. The differences in the temperature of the apples (despite the weather conditions) can be seen in Figure 2, that is, Farm B achieved better results than Farm C even though it experienced warmer weather on the day of the trial. Farm A uses a large storage facility, whilst Farm B uses a loading bay under the trees. Farm $\mathrm{C}$ uses six forklifts, whilst Farm A uses four and Farm B only uses one to load bins onto trailers or trucks. Farm $\mathrm{C}$ uses four trucks that fit 68 bins on, whilst Farm A uses two trucks with the same capacity and Farm B uses one truck that fits 20 bins on it. Farm C can, therefore, transport bins much faster than Farm A and Farm B. The volumes handled on the three different farms are similar.

The effectiveness of pickers, storage facilities on the farm and the availability of trucks to transport the fruit quickly from the farms to the centralised cold storage facility, irrespective of the distance, plays an influential role in the variation of the temperature profile of apples. This can be seen in Figure 3.

\section{Impact of the geographical location of farms on the temperature profile of apples}

The findings of the case study indicate that the geographical location of farms in the Ceres district has an impact on the temperature profile of apples. Farm $\mathrm{C}$ is $52 \mathrm{~km}$ away, the furthest from the centralised cold storage facility. Farm A is 34 $\mathrm{km}$ away and Farm B is $9 \mathrm{~km}$ away. During the transportation phase between the farms and the centralised cold storage facility, the total temperature changes for the two respective days vary from $2.99{ }^{\circ} \mathrm{C}-3.65^{\circ} \mathrm{C}$ for Farm $\mathrm{C}, 1.45^{\circ} \mathrm{C}-1.76{ }^{\circ} \mathrm{C}$ for Farm A and $0.67^{\circ} \mathrm{C}-1.2^{\circ} \mathrm{C}$ for Farm B (shown in Figure 4). This indicates, from a logistical point of view, that the fruit became warmer from the time the apples were picked and left the orchard on a tractor until they were unloaded at the centralised cold storage facility. The transport time differs from each farm and that could influence the temperature change. The height above sea level and where the farms are situated also play a role in the fruit temperature. Farm C is $984.11 \mathrm{~m}$ a.s.l. and lies in the Koue Bokkeveld on a plateau. It is adjacent to a mountain, has a temperature average of $18.89^{\circ} \mathrm{C}$ for the month of March and is the coldest among these three farms. Farm A is $1059.71 \mathrm{~m}$ a.s.l. and is situated in the Droëhoek area between two mountain ranges. It has an average temperature in March of $19.66{ }^{\circ} \mathrm{C}$ and is the second coldest among the three farms. Farm B is $504.31 \mathrm{~m}$ a.s.l. and is situated at the foot of the Ceres Peak Mountain in the Ceres valley. Its average March temperature was $20.88^{\circ} \mathrm{C}$ and had a generally higher temperature than the other two farms as shown in Figure 4 (De Vries 2015).

\section{Optimal trade-off between the time of picking and fruit quality}

The trade-off between time of harvesting in the early morning and fruit quality must be made. The early morning temperature is quite low in the Ceres district. This is ideal because the faster the apples are picked and transported to the cold storage facility, where the temperature to the optimum level prescribed by the PPECB, the higher the quality of the fruit yield. As the day passes, the temperature of the apples rises and it becomes more difficult to achieve the recommended $-0.5{ }^{\circ} \mathrm{C}$ within 48 hours. However, according to Crouch (2003), bruise prone fruits such as Golden Delicious apples are picked in the late morning when the dew has evaporated from the fruit and the temperature of apples are higher, causing less damage. Bruising is one of the main factors affecting the fruit quality of Golden Delicious apples (Zarifneshat et al. 2010).

According to Findlay (1992), as the Golden Delicious apple becomes softer and more mature, because of higher temperatures resulting in a higher deterioration rate, the potential for bruising increases. Apples picked after rain or with soil moisture at full capacity will bruise far more easily than when picked on a falling moisture regime (Findlay 1992). The orchards at Farm A and Farm B are denser than Farm C, which causes a lot more moisture in the early morning, not only on the apples, but it also has a great influence on the soil moisture. Apples picked in the early

\begin{tabular}{|c|c|c|c|c|c|c|}
\hline & \multicolumn{2}{|c|}{ Farm A } & \multicolumn{2}{|c|}{ Farm B } & \multicolumn{2}{|c|}{ Farm C } \\
\hline Variety & Goldens & Grannys & Goldens & Grannys & Goldens & Grannys \\
\hline Date & 05-Mar & 30-Mar & 06-Mar & 23-Mar & 07-Mar & 31-Mar \\
\hline Day's forecasted average temperature on farm when picked & $19.602^{\circ} \mathrm{C}$ & $20.308^{\circ} \mathrm{C}$ & $20.329^{\circ} \mathrm{C}$ & $19.758^{\circ} \mathrm{C}$ & $17.108^{\circ} \mathrm{C}$ & $20.512^{\circ} \mathrm{C}$ \\
\hline Average temperature for the month of March & \multicolumn{2}{|c|}{$19.66^{\circ} \mathrm{C}$} & \multicolumn{2}{|c|}{$20.88^{\circ} \mathrm{C}$} & \multicolumn{2}{|c|}{$18.89^{\circ} \mathrm{C}$} \\
\hline Average wind-speed during the day of picking & $1.307 \mathrm{~km} / \mathrm{h}$ & $1.277 \mathrm{~km} / \mathrm{h}$ & $1.185 \mathrm{~km} / \mathrm{h}$ & $0.964 \mathrm{~km} / \mathrm{h}$ & $1.560 \mathrm{~km} / \mathrm{h}$ & $1.179 \mathrm{~km} / \mathrm{h}$ \\
\hline Kilometers from the centralised cold storage facility & \multicolumn{2}{|c|}{$34 \mathrm{~km}$} & \multicolumn{2}{|c|}{$9 \mathrm{~km}$} & \multicolumn{2}{|c|}{$52 \mathrm{~km}$} \\
\hline Height above sea level & \multicolumn{2}{|c|}{1059.71 metres } & \multicolumn{2}{|c|}{504.31 metres } & \multicolumn{2}{|c|}{984.11 metres } \\
\hline Transportation part 1: ${ }^{\circ} \mathrm{C}$ as apples leave orchard on tractor & $15.19^{\circ} \mathrm{C}$ & $15.66^{\circ} \mathrm{C}$ & $15.75^{\circ} \mathrm{C}$ & $17.61^{\circ} \mathrm{C}$ & $14.48^{\circ} \mathrm{C}$ & $16.75^{\circ} \mathrm{C}$ \\
\hline Transportation part 2: ${ }^{\circ} \mathrm{C}$ when apples are loaded onto truck & $16.20^{\circ} \mathrm{C}$ & $16.51^{\circ} \mathrm{C}$ & $15.99^{\circ} \mathrm{C}$ & $18.01^{\circ} \mathrm{C}$ & $14.65^{\circ} \mathrm{C}$ & $16.65^{\circ} \mathrm{C}$ \\
\hline Transportation part 3: ${ }^{\circ} \mathrm{C}$ when unloaded at the centralised cold storage facility & $16.95^{\circ} \mathrm{C}$ & $17.11^{\circ} \mathrm{C}$ & $16.95^{\circ} \mathrm{C}$ & $18.28^{\circ} \mathrm{C}$ & $18.13^{\circ} \mathrm{C}$ & $19.74^{\circ} \mathrm{C}$ \\
\hline Total temperature changes during the transportation phase & $1.76^{\circ} \mathrm{C}$ & $1.45^{\circ} \mathrm{C}$ & $1.2^{\circ} \mathrm{C}$ & $0.67^{\circ} \mathrm{C}$ & $3.65^{\circ} \mathrm{C}$ & $2.99^{\circ} \mathrm{C}$ \\
\hline
\end{tabular}

Source: Hortec, 2015, Designed and managed martin-endemann.com. 'Hortec/Weather Service', Hortec.co.za, viewed 29 March 2015, from http://www.hortec.co.za/weatherservices.html FIGURE 4: Geographical information on picking day for Farm A, Farm B and Farm C. 
morning bruise more easily than those picked after they have warmed up during the day (Findlay 1992). The average temperature at 06:00 on the days of the trials was $7.34{ }^{\circ} \mathrm{C}$, whilst at 10:00 it was $13.41^{\circ} \mathrm{C}$. As mentioned above, Golden Delicious apples maintain their temperature much more consistently than other apple varieties (Jordan 2015).

Time of harvesting apples is crucial and one must choose between maintaining a low temperature by harvesting in the early morning or ensuring there are fewer bruises and a better quality fruit by waiting the dew out. This is where the trade-off comes in between harvesting in the early morning for optimum temperature or later to obtain higher fruit quality.

\section{Conclusion}

The study identified that logistic processes have an impact in terms of the temperature profile of apples in the first 48 hours post-harvest. The analysis of the temperature trials, observations and interviews revealed that the temperature profile of apples is an important factor for the grower to take note of, because it directly impacts the quantity and quality of fruit yield. Two different apple varieties, namely Golden Delicious and Granny Smith, on three different farms were investigated. Various factors play a role in affecting the temperature profile of apples. In this study, the geographical location of farms (Kouebokkeveld, Droëhoek and Ceres valleys) is considered, along with different methods of loading, unloading and transportation on and from farms and at the centralised cold storage facility. The trade-off between the time of harvesting and the fruit quality of Golden Delicious apples also has an impact on the temperature profile of apples.

Time of harvesting apples is crucial and it is important to choose between maintaining a low temperature by harvesting in the early morning or ensuring that there are fewer bruises and thus a better quality fruit, by waiting the dew out. A key finding is that, it is not only at what time the apples are being picked, but also at what time the apples are placed under cooling conditions to remove the field heat to obtain the recommended temperature profile within 48 hours. In addition, it was identified that effective and efficient picking at the right time (especially between 07:00 and 09:00), and the transportation of the apples directly or as soon as possible after the apples came out of the orchard to the centralised cold storage facility, are key in ensuring the quality of the fruit and the temperature profile necessary for export. Another key finding is that the bins should not be left to stand in the sun after harvesting. By placing an iButton ${ }^{\circledR}$ on the inside and on the outside of an apple, it was identified that the fruit cools down faster on the outside than on the inside. To cool the core down faster, the fruit must be put in cold storage quicker.

\section{Implications, recommendations and future work}

The timeframe for harvesting apples is $4-6$ days. This meant that there was only sufficient time to conduct one trial per farm per variety. If more than one person could do the same trial (more apples per trial) on the same day, on different farms, more accurate data and conclusions could have been drawn.

The iButton ${ }^{\circledR}$ device is sensitive and its readings spike when touched by hand, because of body heat. One possible reason for the trials indicating that the apple temperatures did not cool down to within the correct standard within 48 hours could be that the body heat that was given off whilst placing the iButton ${ }^{\circledR}$ gave an erroneously high-temperature reading. The process of insertion takes longer than just to pick the apple, because it is necessary to first cut a hole where the iButton ${ }^{\circledR}$ can fit and this causes a spike in temperature. To do this trial more accurately, the device must be put in faster to spend less time touching the iButton ${ }^{\circledR}$.

The RA cold storage rooms were opened and closed regularly, which meant that the room lost its coldness, and could explain why the fruit was not cooled to $-0.5{ }^{\circ} \mathrm{C}$ within the 48 hours after picking. This identified that the apple industry needs to be aware of the effect that opening the cold storage doors in RA rooms too often is having on the temperature profile and potentially the quality of their export fruit. To further this study, temperature monitoring devices can be placed on fruit that is to be stored in a CA cold storage room, but this storage is for long-term purposes only and could mean that the data are not reachable within the timeframe required.

It would be beneficial to record the temperature readings (specifically) for each segment of the supply chain depicted in Figure 1 along with the temperature readings taken every 6 hours (shown in Figure 2). This would determine the contribution that each section of the supply chain has on the temperature profile of apples and would provide a better understanding of the supply chain and logistical methods that can influence the temperature profile of apples. Further research is required to determine the monetary value farmers lose if they do not pick and deliver their fruit in a certain timeframe, as well as research to determine the monetary value lost if fruit reaches maturity faster and what the quality aspects of this are.

\section{Acknowledgements Competing interests}

The authors declare that they have no financial or personal relationships that may have inappropriately influenced them in writing this article.

\section{Authors' contributions}

A.G.D.T.V. conducted the research as part of his Honours degree. L.L.G-G. acted as the supervisor for the Honours research. She also wrote the article from the research conducted.

\section{References}

Ahmad, M.S. \& Siddiqui, M.W., 2016, Postharvest quality assurance of fruits, Springer International Publishing, Switzerland. http://dx.doi.org/10.1007/978-3-319-21197-8_2 Arin, S. \& Akdemir. S., 2004, 'Quality properties changing of grape during storage period', Journal of Biological Sciences 4(2), 253-257. 
Bartsch, J.A. \& Blanplied, G.D., 1984, Refrigeration and controlled atmosphere storage for horticultural crops, viewed 26 August 2016, from http://archive.lib msu.edu/ DMC/Ag.\%20Ext.\%202007-Chelsie/PDF/e1914-ND.pdf

Birch, S.M., 1993, A guide to deciduous fruit of the Cape, ABC Press, Epping.

Ceres.org.za., 2015, Climate, viewed 07 March 2015, from http://www.ceres.org.za/ about-ceres/climate.html

Crouch, I., 2003, 'Post-harvest apple practices in South Africa', in Washington Tree Fruit Postharvest Conference, WSU -TFREC Post-Harvest Information Network, Wenatchee, Washington, DC, December 02-03, 2003, p. 1.

Department for Environment, Food and Rural Affairs, n.d., Apple best practice guide, viewed 26 August 2016, from http://apples.ahdb.org.uk/post-harvestsection6.asp

Findlay, J., 1992, Bruising and its control, Hortgro Science, viewed 15 August 2016 from http://www.hortgro-science.co.za/wpcontent/uploads/2014/11/ bruising___findlay_1992_12.pdf

Food and Agriculture Organisation of the United Nations, 2016, Deciding on packaging for fresh produce, viewed 14 August 2016, from http://www.fao.org/docrep/ t0073e/T0073E04.htm

Freiboth, H.W., Goedhals-Gerber, L.L., Van Dyk, F.E. \& Dodd, M.C., 2013, 'Investigating temperature breaks in the summer fruit export cold chain: A case study', Journal of Transport and Supply Chain Management 7(1), Art. \#99, 1-7. http://dx.doi. org/10.4102/jtscm.v7i1.99

Goedhals-Gerber, L.L., 2015, Post-harvest seminar, Stellenbosch: Fresh NOTES, pp. 10 11, viewed 03 March 2015, from http://www.hortgro-science.co.za/wp-content/ uploads/2014/07/Fresh-Note-106.pdf

Grant, A., 2016, Tips for harvesting apples and post-harvest apple storing, viewed 16 August 2016, from http://www.gardeningknowhow.com/edible/fruits/apples/ harvesting-and-storing-apples.htm

Haasbroek, L., 2013, An analysis of temperature breaks in the summer fruit export cold chain from pack house to vessel, Scholar.sun.ac.za, viewed 16 February 2015, from http://scholar.sun.ac.za/handle/10019.1/85676

Hortec, 2015, Designed and managed martin-endemann.com. 'Hortec/Weather Service', Hortec.co.za, viewed 29 March 2015, from http://www.hortec.co.za/ weatherservices.html

Hortgro, 2015, Stone Fruit Steenvrugte - Hortgro, viewed 04 April 2015, from http:// www.hortgro.co.za/production-techical-information/technical-information/ handling-protocols/stone-fruit/
Intelliflex, 2012, Temperature management and the cold supply chain: Improving quality, shelf-life and revenues with Pallet-level monitoring of fresh produce,
viewed 17 February 2016, from http://www.rfid24-7.com/wp-content/ uploads/2012/07/INTELLEFLEX-TemperatureManagementCold-Chain.pdf

Jobling, J., 2002, Postharvest management of fruit and vegetables, viewed 03 June 2015, from http://www.postharvest.com.au/postharvest.pdf

Kansal, A., 2014, Factors affecting pricing and marketing, viewed 26 August 2016 from http://shodhganga.inflibnet.ac.in/bitstream/10603/17886/7/chapter\%206. pdf

Mowat, A.D. \& Kay, C., 2007, Geographic patterns in fruit attributes for New Zealand grown kiwifruit, viewed 17 August 2016, from http://www.actahort.org/ books/753/753_40.htm

Ngcobo, L., 2010. Ports \& ships, viewed 30 June 2015, from http://www.ports.co.za

Perishable Products Export Control Board (PPECB), 2015, PPECB, viewed 13 July 2015, from http://www.ppecb.com

Shahidi, F., Spanier, A.M., Ho, C.-T. \& Braggins, T., 2004, Quality of fresh and processed foods, Kluwer Academic, New York.

Siddiqui, M.W., Zavala, J.F.A. \& Hwang, C-A.A., 2016, Postharvest management approaches for maintaining quality of fresh produce, Springer International Publishing, Switzerland.

Thompson, J.F., 2002, 'Storage systems', in A.A. Kader (ed.), Postharvest technology of horticulture crops, pp. 113-128, Agriculture and Natural Resources, University of California., Davis, California.

Thompson, J.F., Mitchell, F.G., Rumsey, T.R., Kasmire, R.F. \& Crisosto, C.H., 2008, Commercial cooling of fruits, vegetables, and flowers, rev. edn. pp. 1-7, Agriculture and Natural Resources, University of California, Davis, California.

Valentine, A.G.D., 2015, The temperature profile of an apple supply chain, from the picking process until 48 hours after picking: A case study of the Ceres district, Unpublished Honours Assignment. Stellenbosch, Stellenbosch University.

Vigneault, C. Thompson, J., Wu, S., Hui, K.P.C. \& LeBlanc, D.I. 2009, 'Transportation of fresh horticultural produce', in N. Benkeblia (ed.), Postharvest technologies for horticultural crops, vol. 2, pp. 1-24, Research Signpost, Kerala, India.

Zarifneshat, S., Ghassemzadeh, H.R., Sadeghi, M., Abbaspour-Fard, M.H., Ahmadi, E., Javadi, A. et al., 2010, 'Effect of impact level and fruit properties on golden delicious apple bruising', American Journal of Agricultural and Biological Sciences 5(2), 114-121. http://dx.doi.org/10.3844/ajabssp.2010.114.121 